\title{
Frequent exacerbators - a distinct phenotype of severe asthma
}

M. Kupczyk ${ }^{1,10}$, A. ten Brinke ${ }^{2}$, P. J. Sterk ${ }^{3}$, E. H. Bel ${ }^{3}$, A. Papi ${ }^{4}$, P. Chanez ${ }^{5}$, E. Nizankowska-Mogilnicka ${ }^{6}$, M. Gjomarkaj ${ }^{7}$, M. Gaga ${ }^{8}$, G. Brusselle ${ }^{9}$, B. Dahlén ${ }^{1}$, S.-E. Dahlén ${ }^{1}$ and on behalf of the BIOAIR investigators*

${ }^{1}$ Center for Allergy Research, Division of Respiratory Medicine and Allergy, Department of Medicine, Karolinska Institutet, Stockholm, Sweden,

${ }^{2}$ Department of Pulmonology, Medical Centre Leeuwarden, Leeuwarden, The Netherlands, ${ }^{3}$ Department of Respiratory Medicine, Academic Medical Centre, University of Amsterdam, Amsterdam, The Netherlands, ${ }^{4}$ Section of Respiratory Diseases, Department of Medical Sciences, University of Ferrara, Ferrara, Italy, ${ }^{5}$ Department of Respiratory Diseases, University of Marseille, Marseille, France, ${ }^{6}$ Department of Medicine, Jagiellonian University, Krakow, Poland, ${ }^{7}$ Institute of Biomedicine and Molecular Immunology, Italian National Research Council, Palermo, Italy, ${ }^{8} 7$ th Respiratory Department and Asthma Centre, University of Athens, Athens, Greece, ${ }^{9}$ Department of Respiratory Medicine, Ghent University Hospital, Ghent, Belgium and ${ }^{10}$ Department of Internal Medicine, Asthma and Allergy, Medical University of Lodz, Lodz, Poland

\section{Clinical Et
Experimental
Allergy}

Correspondence:

Maciej Kupczyk, Centre for Allergy Research, Karolinska Institutet, IMM Physiology P.O. Box 287, SE-171 77 Stockholm, Sweden. E-mail: maciek.kupczyk@ki.se Cite this as: M. Kupczyk, A. ten Brinke, P. J. Sterk, E. H. Bel, A. Papi, P. Chanez, E. Nizankowska-Mogilnicka, M. Gjomarkaj, M. Gaga, G. Brusselle, B. Dahlén, S.-E. Dahlén and on behalf of the BIOAIR investigators, Clinical \&t Experimental Allergy, 2014 (44) 212-221.

\section{Summary}

Background Exacerbations represent a major source of morbidity and mortality in asthma and are a prominent feature of poorly controlled, difficult-to-treat disease.

Objective The goal of our study was to provide a detailed characterization of the frequent exacerbator phenotype and to identify risk factors associated with frequent and seasonal exacerbations.

Methods Ninety-three severe asthmatics (SA) and 76 mild-to-moderate patients (MA) were screened and prospectively followed up for 1 year (NCT00555607). Medical history, baseline clinical data and biomarkers were used to assess risk factors for frequent exacerbations.

Results During the study, 104 exacerbations were recorded in the SA group and 18 in the MA. Frequent exacerbators were characterized by use of higher doses of inhaled (1700 vs. $800 \mu \mathrm{g}$ ) and oral (6.7 vs. $1.7 \mathrm{mg}$ ) glucocorticosteroids, worse asthma control (ACQ score 2.3 vs. 1.4), lower quality of life (SGRQ score 48.5 vs. 33.3), higher sputum eosinophils $(25.7 \%$ vs. $8.2 \%)$ and a more rapid decline in $\mathrm{FEV}_{1} / \mathrm{FVC}$ ratio ( -0.07 vs. $-0.01 \Delta \mathrm{FEV}_{1} /$ FVC, frequent vs. non-frequent, respectively, $P<0.05$ ). Exhaled NO $>45$ p.p.b. and a history of smoking were associated with an increased risk of frequent exacerbations (odds ratios: 4.32 and 2.90 respectively).

Conclusion and Clinical Relevance We were able to distinguish and characterize a subphenotype of asthma subjects - frequent exacerbators - who are significantly more prone to exacerbations. Patients with FeNO > 45 p.p.b. and a history of smoking are at increased risk of frequent exacerbations and require careful monitoring in clinical practice.

Keywords asthma exacerbation, risk factors for exacerbations, severe asthma Submitted 8 January 2013; revised 13 June 2013; accepted 27 June 2013

\section{Introduction}

Acute exacerbations are a major source of morbidity and mortality in asthma. It has been shown in children that the costs associated with asthma care are three times higher in exacerbators as compared to those patients

${ }^{*}$ Contributors to the BIOAIR (Longitudinal Assessment of Clinical Course and BIOmarkers in Severe Chronic AIRway Disease) study are listed in the Appendix. who did not experience any attacks [1]. Exacerbations are a prominent feature of poorly controlled and severe asthma [2]; however, even in patients with mild disease, the rates of severe exacerbations are high [3]. Recent ATS/ERS guidelines [4] pointed out that exacerbations constitute the greatest risk to patients, are the major cause of stress and anxiety to patients and their families, and generate the highest costs for the health care system.

Nowadays, a history of exacerbations is incorporated into the definition of asthma control and the prevention of asthma exacerbations has been identified as a pri- 
mary goal in asthma treatment guidelines [5]. Improving baseline asthma control with inhaled glucocorticosteroids can reduce the risk of exacerbations in patients with atopic asthma. However, a decrease in asthma symptoms is not always in line with the number or severity of exacerbations [6]. Thus, it has been hypothesized that baseline disease control and mechanisms underlying exacerbations are probably driven by different factors [2]. In clinical practice, one can easily recognize a subgroup of asthma patients that experience a higher rate of exacerbations.

In contrast to chronic obstructive pulmonary disease [7], the phenotype of frequent exacerbators has not been clearly characterized in asthma patients. Thus, the primary goal of our study was to provide detailed characteristics of frequent exacerbators based on medical history, physiological variables and biomarkers. Secondary goals included the identification of risk factors associated with frequent exacerbations, and a detailed analysis of seasonal (autumn and spring) exacerbations. As two different definitions of frequent exacerbations (more than two events per year [2] or more than three events per year [8]) are currently in use, we also aimed to study potential differences in those two approaches.

\section{Methods (for further details, please refer to the Supporting Information)}

\section{Study design}

The BIOAIR trial was a partly European Union supported project on biomarkers and clinical outcomes, with a particular focus on severe asthma. The study had a twogroup prospective design. Asthma patients were screened and allocated to severe (SA) or mild-to-moderate asthma (MA) cohorts. After a 4-week treatment optimization period, patients were followed up for at least 1 year. Information regarding lung function, biomarkers (induced sputum, peripheral blood, exhaled NO), atopy, medical history, asthma control (evaluated with the use of the Juniper Asthma Control Questionnaire) [9] and quality of life (evaluated with the use of St Georges Respiratory Questionnaire) [10] were collected at baseline and at consecutive visits. The study was registered at the clinicaltrials.gov web (NCT00555607) and the protocol was approved by the ethics review boards and drug regulatory authorities in the twelve participating centres.

\section{Subjects}

Asthma was diagnosed by pulmonary specialists according to standard criteria [5, 11]. Patients included in the SA group had been under specialist treatment for at least 1 year and despite continuous treatment with high doses of inhaled corticosteroids (ICS; at least
$1600 \mu \mathrm{g} /$ day budesonide or equivalent) had experienced at least one exacerbation requiring oral steroid treatment in the year preceding inclusion into the study. Patients in the MA group had stable disease, received daily treatment with a maximum of $800 \mu \mathrm{g} /$ day budesonide, used short-acting $\beta$-agonists (SABA) as needed but did not require treatment with LABA and had had neither exacerbations nor hospitalizations in the last year. All patients gave written informed consent.

\section{Exacerbations}

In line with the ATS/ERS recommendations [4], exacerbations were defined as events clinically identified to be outside the patient's usual range of day-to-day asthma variation, which are troublesome for patients and require a change in treatment. Severe exacerbations (including at least 3 days' use of oral corticosteroids, an increase from a maintenance dose of systemic corticosteroids, or hospitalizations/ED visits) and moderate exacerbations (defined as a need for change in treatment, but not fulfilling the criteria of severe exacerbations) were included in the analysis. Mild asthma exacerbations were not identified as they could not be distinguished from a transient loss of asthma control [4]. Frequent exacerbators were defined as those who had two or more exacerbations during the 1 year of follow-up, and nonfrequent exacerbators as those who had no exacerbations or up to 1 event. Spring exacerbators were defined as those who experienced most of exacerbations in April, May or June, and likewise autumn exacerbators as those with most exacerbations in October, November and December. Non-seasonal exacerbators had events- in other months during the 1 year follow-up period.

\section{Data collection and statistical analysis}

Lung function (PEF and FEV1), rescue medication use (SABA), day and night symptoms and limitation of activities were recorded daily using electronic diaries (Vitalograph Electronic PEF/FEV1 Diary - XM version, Vitalograph Ltd., Buckingham, UK). During the study, the patients were supplied with written cards advising them to contact the study physician or nurse immediately (all centres were available $24 \mathrm{~h} /$ day and 7 day/week) in case of a troublesome loss of asthma control (increase in symptoms and rescue medication use, decrease in daily activities, or quality of life). Weekly phone calls were made by study nurse to ensure the patients' compliance with the study procedures. Based on medical history, symptoms, medication use and additional tests, the responsible physician then labelled the event as an asthma exacerbation. Data were entered into a central database through a web-based Case Record Form (eCRF) system developed specifically for the BIOAIR study. 
Patients' baseline characteristics are expressed as mean \pm standard error of the mean (SEM). Non-parametric tests (Mann-Whitney $U$-test) and chi-square tests (or Fishers exact test where appropriate) were used.

To identify factors possibly associated with a risk of frequent or seasonal exacerbations, subjects with reported exacerbations were compared with applicable controls (non-frequent or non-seasonal exacerbators). A multivariate logistic regression model including all potential predictors with a univariate $P$-value less than 0.1 was built and adjusted for atopy, sex, age, asthma severity and smoking status. SPSS version 17.0 software (SPSS Inc., Chicago, IL, USA) was used for statistical analysis. $P<0.05$ was considered a statistically significant difference for all tests. A subanalysis of frequent exacerbators, including patients with three or more exacerbations was also performed and compared to the whole group of frequent exacerbators (two or more events).

\section{Results}

\section{Patients' characteristics}

One hundred and sixty-nine patients, including 93 SA and $76 \mathrm{MA}$, were screened and followed up for at least 1 year. Baseline patient characteristics and demographic data are displayed in Table 1 . Severe asthmatics, in comparison to MA, were older (50 vs. 42.2 years), had a higher BMI (28.5 vs. 25.0), lower lung function ( $\mathrm{FEV}_{1} \%$ of predicted: 70.4 vs. $88.7 \%$ ) and poorer quality of life (Juniper ACQ score 2.03 vs. 1.03). Severe asthma patients were significantly older when their asthma developed (29.2 vs. 22.2, SA vs. MA).

\section{Exacerbations}

The majority of exacerbations were recorded in the SA group (104 vs. 18 in MA, $P<0.0001$ ). Fifty-two SA patients (56\% of the cohort) experienced 1-6 exacerbations during the 1 year follow-up period. The number of exacerbations per patient per year was 1.2. Fortyone patients from the SA group did not have any exacerbations. Forty-four exacerbations (42.3\%) were regarded as severe based on the predetermined criteria [4], and in 14 cases (13.7\%) hospitalization was necessary. During the 1 year follow-up period, only 16 patients in the MA cohort $(22.2 \%)$ had in total 18 exacerbations. The number of exacerbations per patient per year was 0.24. Five exacerbations were severe (27.8\%). No hospitalizations due to asthma exacerbations were reported in the MA group. Thirty one exacerbations were recorded in spring time (April, May and

Table 1. Demographic data and baseline characteristics of the BIOAIR study cohort [mean values ( \pm SEM), unless stated differently]. Atopy defined as at least one positive skin prick test.

\begin{tabular}{|c|c|c|c|c|}
\hline & Whole study group & Severe asthma (SA) & $\begin{array}{l}\text { Mild-to-moderate } \\
\text { asthma (MA) }\end{array}$ & $\begin{array}{l}P \text { (SA vs. } \\
\text { MA) }\end{array}$ \\
\hline Number of patients $(n)$ & 169 & 93 & 76 & - \\
\hline Number of exacerbations ( $n$, mean \pm SEM) & $122(0.72 \pm 0.09)$ & $104(1.2 \pm 1.1)$ & $18(0.24 \pm 0.2)$ & $<0.0001$ \\
\hline Age (years) (min-max) & $46.5 \pm 1.04(18-72)$ & $50.0 \pm 1.3(18-72)$ & $42.2 \pm 1.5(20-70)$ & 0.0002 \\
\hline Females (\%) & 59.2 & 58 & 61 & $0.76^{*}$ \\
\hline Age of asthma onset (years) & $26.1 \pm 1.9$ & $29.2 \pm 1.9$ & $22.2 \pm 2.2$ & 0.01 \\
\hline $\mathrm{FEV}_{1}(\%$ pred $)$ & $80.1 \pm 1.8$ & $70.4 \pm 2.1$ & $88.7 \pm 2.1$ & $<0.0001$ \\
\hline $\mathrm{FEV}_{1}(\mathrm{~L})$ & $2.44 \pm 0.07$ & $2.04 \pm 0.08$ & $2.79 \pm 0.08$ & $<0.0001$ \\
\hline $\mathrm{FEV}_{1} / \mathrm{FVC}$ & $0.69 \pm 0.01$ & $0.67 \pm 0.01$ & $0.70 \pm 0.01$ & 0.035 \\
\hline Reversibility & $9.97 \pm 0.5$ & $9.4 \pm 0.8$ & $10.6 \pm 0.7$ & 0.09 \\
\hline $\begin{array}{l}\text { ICS [median (mean } \pm \text { SD)] } \mu \mathrm{g} \text { beclomethasone } \\
\text { eq. }\end{array}$ & $800(1416 \pm 1015)$ & $1600(2064 \pm 939.7)$ & $800(614 \pm 218.6)$ & $<0.0001$ \\
\hline $\begin{array}{l}\text { OCS [median (mean } \pm \text { SD; min-max)] } \\
\text { prednisolone eq. }\end{array}$ & $0 \mathrm{mg}(2.6 \pm 7.6 ; 0-50)$ & $10 \mathrm{mg}(14.1 \pm 11.8 ; 2-50)$ & - & - \\
\hline BMI $\left(\mathrm{kg} / \mathrm{m}^{2}\right)$ & $27.0 \pm 0.4$ & $28.5 \pm 0.6$ & $25.0 \pm 0.4$ & $<0.0001$ \\
\hline ACQ (Juniper, units) & $1.6 \pm 0.1$ & $2.03 \pm 0.1$ & $1.03 \pm 0.7$ & $<0.0001$ \\
\hline QoL (SGRQ, units) & $36.3 \pm 1.8$ & $45.9 \pm 2.1$ & $22.5 \pm 2.0$ & $<0.0001$ \\
\hline CRP (mg/L) & $4.9 \pm 0.6$ & $6.1 \pm 0.9$ & $3.5 \pm 0.6$ & 0.01 \\
\hline Atopy $(\%)$ & 45.0 & 43.2 & 48.0 & $0.64^{*}$ \\
\hline $\mathrm{F}_{\mathrm{E}} \mathrm{NO}$ (p.p.b.) & $43.5 \pm 3.9$ & $46.3 \pm 6.2$ & $40.1 \pm 4.1$ & 0.91 \\
\hline Smoking status (pack years history) & $5.0 \pm 0.9$ & $4.7 \pm 1.1$ & $5.6 \pm 1.8$ & 1.0 \\
\hline Sputum cells $\left(\times 10^{6}\right)$ & $2.5 \pm 0.6$ & $3.34 \pm 1.02$ & $1.83 \pm 0.34$ & 0.38 \\
\hline Sputum eosinophils (\%) & $11.4 \pm 2.1$ & $16.7 \pm 3.49$ & $5.79 \pm 1.71$ & 0.026 \\
\hline Sputum neutrophils (\%) & $43.2 \pm 2.8$ & $42.2 \pm 3.7$ & $44.2 \pm 4.4$ & 0.81 \\
\hline
\end{tabular}

Mann-Whitney $U$-test or *chi-square test (for details, see Supporting Information and references S1, S2, S3). 


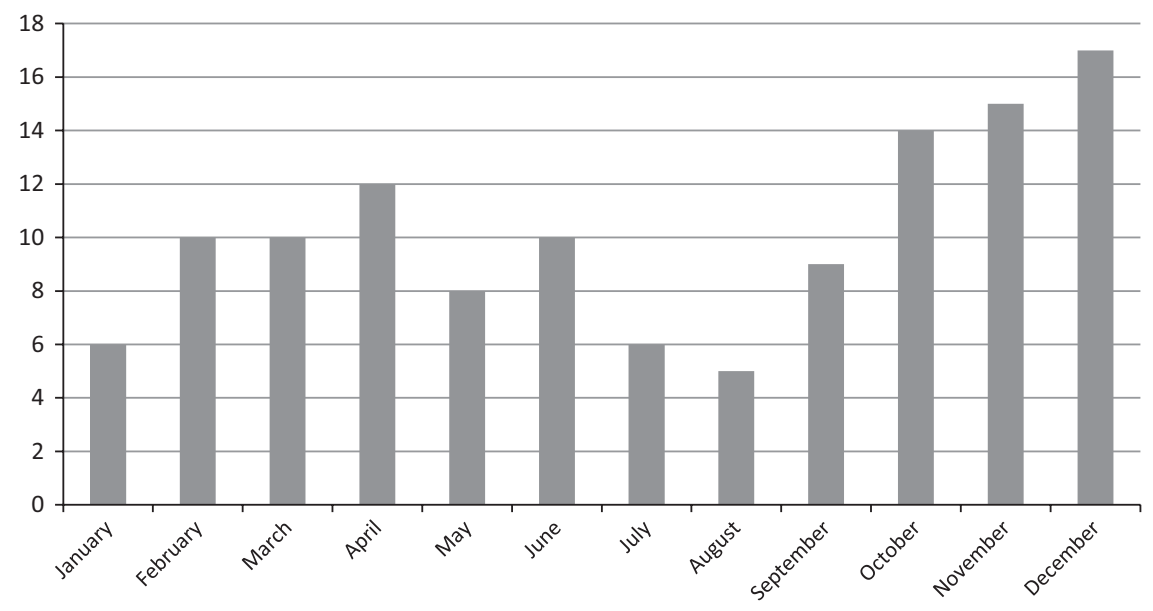

Fig 1 . The monthly distribution of exacerbations over 1 year of follow up.

June), 46 in autumn (October, November and December) and 45 were outside of these seasons (other months) (Fig. 1).

\section{Frequent exacerbators}

Thirty patients experienced at least two, and 14 patients had at least three exacerbations during the 1 year follow-up period, and these were therefore classified as frequent exacerbators. One hundred and thirty-nine patients had less than two exacerbations and were classified as non-frequent exacerbators. The majority of frequent exacerbators were from the SA cohort. Frequent exacerbators used significantly higher doses of inhaled $(1700$ vs. $800 \mu \mathrm{g})$ and oral (6.7 vs. $1.7 \mathrm{mg})$ glucocorticosteroids, had worse asthma control (ACQ score 2.3 vs. 1.4), a lower quality of life (SGRQ score 48.5 vs. 33.3), higher CRP level (6.8 vs. $4.3 \mathrm{mg} / \mathrm{L}$ ) and higher sputum eosinophils (25.7 vs. 8.2\%) at baseline as compared with non-frequent exacerbators (Table 2). No significant differences in baseline characteristics were found between frequent exacerbators defined by two or more, and those defined by three or more exacerbations (Table 2).

\section{Change in lung function in frequent exacerbators}

The changes in lung function parameters measured over the 1 year follow-up period ( $\Delta$ calculated as value at visit after 1 year - value at baseline) were compared between non-frequent and frequent exacerbators (Table S2). A statistically significant, more rapid decline in pre-bronchodilator $\mathrm{FEV}_{1} / \mathrm{FVC}$ ratio was found in frequent exacerbators $\left(\Delta \mathrm{FEV}_{1} / \mathrm{FVC}=-0.07\right.$ vs. -0.01 in frequent vs. non-frequent, respectively, $P=0.02$, Mann-Whitney $U$-test). A tendency towards a faster decline in $\mathrm{FEV}_{1} \%$ of predicted $\left(\triangle \mathrm{FEV}_{1} \%\right.$ predicted $=-8.8$ vs. -4.8 , in frequent vs. non-frequent exacerbators) and $\mathrm{FVC} \%$ of predicted $(\triangle \mathrm{FVC} \%$ predicted $=-6.6$ vs. 2.8 ) was seen; however, these differences did not reach statistical significance $(P=0.1$ and $P=0.64$ respectively).

\section{Risk factors for frequent exacerbations}

The univariate analysis of factors associated with a risk of frequent exacerbations is presented in Table S4. When adjusted for possible confounding factors (age, smoking, atopy, severity of the disease and sex) in a multivariate logistic regression model (Table 3) exhaled NO $>45$ p.p.b. and a history of smoking were significantly associated with an increased risk of frequent exacerbations, defined as two or more events per year (odds ratios: 4.32 and 2.90 respectively) (Fig. 2). History of smoking was significantly associated with an increased risk of frequent exacerbations defined as three or more events per year (odds ratio: 3.61) (Table 3 and Fig. 2). Similarly, when the severe asthma cohort was analysed separately, exhaled NO $>45$ p.p.b. and asthma control (Juniper ACQ > 1.36) were significantly associated with an increased risk of frequent exacerbations defined as two or more events per year (odds ratios: 5.98 and 3.65 respectively). There was a tendency towards an increased risk of exacerbations in past smokers (odds ratio: $2.48, P=0.06$ ) (Table S5). Smoking history was the only factor significantly associated with an increased risk of frequent exacerbations defined as three or more events per year (odds ratio: 3.87) (Table S5).

\section{Frequent exacerbators as a distinct phenotype of asthma}

We have evaluated the allocation of frequent exacerbators to different phenotypes as based on published, up to date algorithms $[12,13]$. When allocation is defined 
Table 2. Comparison between frequent exacerbators defined as at least two or at least three events per year of follow-up [mean values ( \pm SEM), unless stated differently]. Atopy defined as at least one positive skin prick test.

\begin{tabular}{|c|c|c|c|c|c|c|}
\hline & $\begin{array}{l}\text { Non-frequent } \\
\text { exacerbators } \\
\text { (<2 events per year) }\end{array}$ & $\begin{array}{l}\text { Frequent } \\
\text { exacerbators } \\
\text { ( } \geq 2 \text { events per year) }\end{array}$ & $\begin{array}{l}P \text { (non- } \\
\text { frequent } \\
\text { vs. } \\
\text { frequent } \\
{[\geq 2} \\
\text { events per } \\
\text { year] }\end{array}$ & $\begin{array}{l}\text { Frequent } \\
\text { exacerbators } \\
\text { ( } \geq 3 \text { events per year) }\end{array}$ & $\begin{array}{l}P \text { (non- } \\
\text { frequent } \\
\text { vs. } \\
\text { frequent } \\
{[\geq 3} \\
\text { events per } \\
\text { year] }\end{array}$ & $\begin{array}{l}P \text { (frequent } \\
{[\geq 2 \text { events] }} \\
\text { vs. frequent } \\
{[\geq 3 \text { events }} \\
\text { per year] }\end{array}$ \\
\hline $\begin{array}{l}\text { Number of } \\
\text { patients }(n)\end{array}$ & 139 & 30 & - & 14 & - & - \\
\hline $\begin{array}{l}\text { Asthma severity } \\
\text { (SA/MA) }\end{array}$ & $65 / 74$ & $28 / 2$ & $<0.0001^{*}$ & $14 / 0$ & $<0.0001^{*}$ & $1.0^{*}$ \\
\hline $\begin{array}{l}\text { Number of } \\
\text { exacerbations } \\
(n, \text { mean } \pm \text { SEM) }\end{array}$ & $38(0.3 \pm 0.04)$ & $84(2.8 \pm 0.2)$ & $<0.0001$ & $52(3.7 \pm 0.3)$ & $<0.0001$ & 0.003 \\
\hline $\begin{array}{l}\text { Age (years) } \\
\text { (min-max) }\end{array}$ & $46.3 \pm 1.2(20-72)$ & $47.4 \pm 2.4(18-70)$ & 0.67 & $50.9 \pm 3.3(29-69)$ & 0.25 & 0.39 \\
\hline Females (\%) & 59 & 60 & $1.0^{*}$ & 57 & $1.0^{*}$ & $1.0^{*}$ \\
\hline $\begin{array}{l}\text { Age of asthma } \\
\text { onset (years) }\end{array}$ & $26.0 \pm 1.6$ & $26.4 \pm 3.5$ & 0.91 & $31.9 \pm 5.1$ & 0.29 & \\
\hline $\mathrm{FEV}_{1}$ (\% pred) & $81.25 \pm 2.1$ & $75.4 \pm 3.4$ & 0.09 & $79.0 \pm 4.9$ & 0.52 & 0.55 \\
\hline $\mathrm{FEV}_{1}(\mathrm{~L})$ & $2.47 \pm 0.08$ & $2.31 \pm 0.15$ & 0.35 & $2.36 \pm 0.21$ & 0.63 & 0.75 \\
\hline $\mathrm{FEV}_{1} / \mathrm{FVC}$ & $0.69 \pm 0.01$ & $0.68 \pm 0.02$ & 0.65 & $0.72 \pm 0.02$ & 0.48 & 0.34 \\
\hline Reversibility & $9.9 \pm 0.5$ & $8.9 \pm 1.5$ & 0.22 & $8.4 \pm 2.0$ & 0.4 & 0.99 \\
\hline $\begin{array}{l}\text { ICS [median } \\
\text { (mean } \pm \text { SD)] } \mu \mathrm{g} \\
\text { beclomethasone eq. }\end{array}$ & $800(1281 \pm 950)$ & $1700(2024 \pm 1063)$ & 0.0001 & $2200(2294 \pm 1242)$ & 0.002 & 0.46 \\
\hline $\begin{array}{l}\text { OCS [median } \\
\text { (mean } \pm \mathrm{SD} \\
\text { min-max)] } \\
\text { prednisolone eq. }\end{array}$ & $0(1.7 \pm 5.8 ; 0-40)$ & $0(6.7 \pm 12.5 ; 0-50)$ & 0.005 & $0(8.6 \pm 14.7 ; 0-50)$ & 0.003 & 0.59 \\
\hline BMI $\left(\mathrm{kg} / \mathrm{m}^{2}\right)$ & $26.6 \pm 0.4$ & $28.4 \pm 1.0$ & 0.055 & $30.1 \pm 1.4$ & 0.01 & 0.37 \\
\hline ACQ (Juniper) & $1.4 \pm 0.1$ & $2.3 \pm 0.2$ & $<0.0001$ & $2.1 \pm 0.2$ & 0.01 & 0.58 \\
\hline QoL (SGRQ) & $33.3 \pm 1.9$ & $48.5 \pm 3.8$ & 0.0008 & $52.7 \pm 4.0$ & 0.0008 & 0.49 \\
\hline CRP (mg/L) & $4.3 \pm 0.6$ & $6.8 \pm 1.4$ & 0.046 & $6.6 \pm 1.6$ & 0.07 & 0.77 \\
\hline Atopy (\%) & 45.3 & 40.0 & $0.67^{*}$ & 50.0 & $0.78^{*}$ & $0.74^{*}$ \\
\hline $\mathrm{F}_{\mathrm{E}} \mathrm{NO}$ (p.p.b.) & $38.9 \pm 3.4$ & $60.6 \pm 12.7$ & 0.23 & $54.4 \pm 20.2$ & 0.74 & 0.73 \\
\hline $\begin{array}{l}\text { Smoking status } \\
\text { (pack years history) }\end{array}$ & $4.6 \pm 0.9$ & $5.9 \pm 2.3$ & 0.77 & $3.7 \pm 0.4$ & 0.93 & 0.75 \\
\hline Sputum cells $\left(\times 10^{6}\right)$ & $2.86 \pm 0.7$ & $1.3 \pm 0.3$ & 0.33 & $1.7 \pm 0.8$ & 0.99 & 0.56 \\
\hline $\begin{array}{l}\text { Sputum eosinophils } \\
(\%)\end{array}$ & $8.2 \pm 1.8$ & $25.7 \pm 6.9$ & 0.004 & $21.0 \pm 12.5$ & 0.15 & 0.76 \\
\hline $\begin{array}{l}\text { Sputum neutrophils } \\
(\%)\end{array}$ & $43.6 \pm 3.1$ & $41.3 \pm 7.0$ & 0.76 & $39.2 \pm 13.8$ & 0.79 & 0.89 \\
\hline
\end{tabular}

Mann-Whitney $U$-test or *chi-square test (Fisher exact test when appropriate).

by physiological variables (lung function, reversibility and age of onset of the disease) as proposed by Moore et al. [12], the majority of frequent exacerbators are found in cluster 4 (low baseline lung function, partially reversible) (29.9\%) and cluster 2 (high baseline lung function, not reversible, early onset) (29.9\%), followed by cluster 3 (high baseline lung function, not reversible, late onset) (16.7\%), 5 (16.7\%) and cluster 1 (high baseline lung function, reversible) (6.7\%). When allocation is based on biomarkers, namely eosinophils and neutrophils in induced sputum [13], the majority of fre- quent exacerbators can be found in cluster 4 (high eosinophils and low neutrophils) (44.4\%) and cluster 3 (high eosinophils and high neutrophils) (38.9\%) followed by cluster 1 (low eosinophils and high neutrophils) (11.1\%) and cluster 2 (low eosinophils and low neutrophils) (5.5\%) (Fig. S1).

\section{Seasonal exacerbators}

Nineteen patients experienced most of their exacerbations in the spring (April, May, June) and 46 in autumn 
Table 3. Adjusted odds ratios in multivariate logistic regression models for factors associated with risk of frequent exacerbations (defined as two or more, and three or more exacerbations during 1 year of follow-up).

\begin{tabular}{|c|c|c|c|c|}
\hline Factor & $\mathrm{OR}$ & $95 \% \mathrm{CI}$ & $P$ & Comments \\
\hline eNO > 45 p.p.b. & 4.32 & $1.02-18.31$ & 0.047 & $\begin{array}{l}\text { Adjusted for sex, age, smoking, asthma } \\
\text { severity and atopy }\end{array}$ \\
\hline Smoking & 2.90 & $1.15-7.35$ & 0.025 & Adjusted for sex, age, asthma severity and atopy \\
\hline Sputum eosinophils $\geq 2 \%$ & 3.81 & $0.68-21.43$ & 0.13 & $\begin{array}{l}\text { Adjusted for sex, age, smoking, asthma } \\
\text { severity and atopy }\end{array}$ \\
\hline SGRQ $>34.6$ (median) & 1.61 & $0.52-4.91$ & 0.41 & As above \\
\hline BMI $>25$ & 1.16 & $0.42-3.12$ & 0.77 & As above \\
\hline \multicolumn{5}{|c|}{ Frequent exacerbators (three or more exacerbations) } \\
\hline Smoking & 3.61 & $1.09-11.99$ & 0.036 & Adjusted for sex, age, asthma severity and atopy \\
\hline SGRQ > 34.6 (median) & 3.46 & $0.66-18.29$ & 0.14 & $\begin{array}{l}\text { Adjusted for sex, age, smoking, asthma } \\
\text { severity and atopy }\end{array}$ \\
\hline eNO $>45$ p.p.b. & 1.36 & $0.205-9.05$ & 0.75 & As above \\
\hline $\mathrm{FEV}_{1} \leq 70 \%$ & 0.71 & $0.19-2.54$ & 0.59 & As above \\
\hline
\end{tabular}
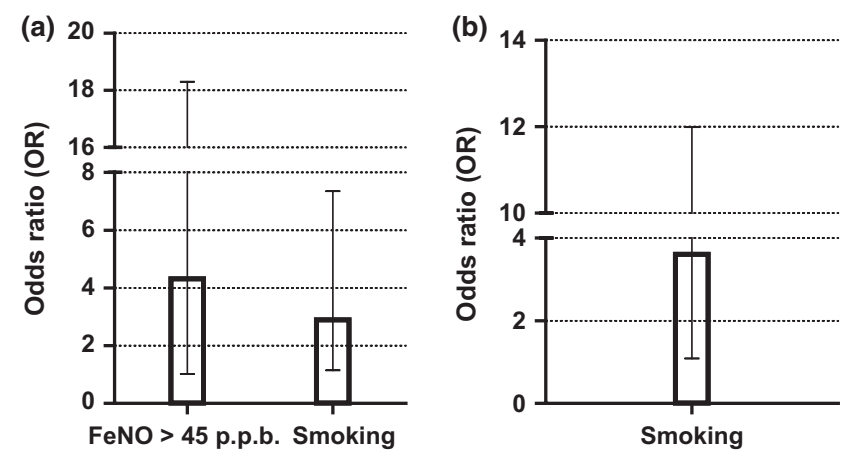

Fig 2. Adjusted odd ratios (and 95\% CI) for risk factors of frequent exacerbations defined as more than two events per year (a) and more than three events per year (b). Multivariate logistic regression model, adjusted for age, sex, asthma severity, smoking and atopy.

(October, November and December), and these patients were classified as seasonal exacerbators (spring and autumn exacerbators respectively) (Fig. 1). A detailed description of seasonal exacerbators and risk factors for seasonal exacerbations is presented in the on-line repository.

\section{Discussion}

Exacerbations are important events in the natural history of poorly controlled asthma. The implications of these flare-ups include risk of mortality, decreased quality of life and extensive utilization of health care resources. In our clinical practice, we can distinguish a subgroup of asthma patients who are significantly more prone to exacerbations. In this article, we propose that these patients should be called 'frequent exacerbators', similar to what has been suggested in COPD patients [14]. In our article, we provide detailed characteristics of the frequent exacerbators' phenotype, based on medical history, physiological variables and biomarkers. We found that frequent exacerbators use higher doses of inhaled and oral glucocorticosteroids, have a lower quality of life and worse asthma control, higher CRP and sputum eosinophil levels. Exhaled NO above 45 p.p.b. and a history of smoking represent risk factors for frequent exacerbations. Thus, we have proven that frequent exacerbators represent a distinct phenotype of asthma, not yet identified by studies published to date, neither based on physiological variables [12] nor on biomarkers [13].

The strength of our study lies in the careful patient selection, prospective design and long (1 year) followup period. Strict diagnostic criteria were applied to recruit a group of patients where all possible comorbidities and alternative diagnoses were carefully excluded, and thus, are unlikely to confound the study results [15]. There are some differences in the basic characteristics of our frequent exacerbators cohort as compared to those described in the study by ten Brinke et al. [8]. In this previous study, it was shown that frequent exacerbators are younger, have a positive family history of asthma, a higher reversibility rate and higher bronchial hyper-reactivity as compared to non-frequent exacerbators. On the other hand, no differences were found when the intensity of treatment was analysed. 
One possible explanation may be that despite the application of similar inclusion criteria in both studies, different populations of asthma patients were included. In the ten Brinke study [8], most of the frequent exacerbators represent a group of younger atopic patients with an early onset of the disease.

We have not found any major differences between phenotypes of frequent exacerbators defined by two or more events [2] or three or more events [8]. We hereby call for a unification of the definitions used in clinical practice and scientific studies, as this would enable more direct comparisons of different trials to be made, as well as improve our understanding of asthma exacerbations. As we found that those asthma patients who experienced two or more exacerbations per year represent a clear phenotype of frequent exacerbators, we propose this definition for frequent exacerbators.

A high proportion of frequent exacerbators in the severe asthmatic group is inherent to the definition of severe, uncontrolled asthma, and in fact, a history of previous exacerbations was an inclusion criterion in our study [11] that has also been used by others [16]. To avoid possible bias, we used asthma severity as a confounding factor in the multivariate analysis. Moreover, we have evaluated risk factors separately for the severe asthma cohort, and these showed no differences compared to the whole study population.

Recent exacerbations represent an important independent predictor of future exacerbations in patients with severe or difficult-to-treat asthma [17]. We have found that despite intensive anti-inflammatory treatment, these patients are still at risk of high numbers of exacerbations, and this is on par with the North-American severe asthma cohort data [18]. Similarly, in the GOAL study, it has been shown that exacerbations could be reduced in the majority of patients by increasing the daily dose of inhaled corticosteroids and LABA. However, in a proportion of patients, it was not possible to achieve good control of the disease on doses of inhaled corticosteroids reaching $1000 \mu \mathrm{g}$ of fluticasone and even oral steroids [19]. In our study, frequent exacerbators were characterized by high levels of sputum eosinophils ( $>25 \%)$ despite intensive treatment $(>2000 \mu \mathrm{g}$ of beclomethasone). This suggests that the recommended treatment may not be efficacious in reducing the level of eosinophilic inflammation in the airways and the rate of exacerbations in this phenotype. Recent trials showed that use of the anti-interleukin (IL)-5 monoclonal antibody (mepolizumab) [20-22] or anti-tumour necrosis factor $\alpha$ [22] may represent a promising strategy. Another option includes the administration of high doses of systemic corticosteroids, as it has been proven that persistent sputum eosinophilia is not a refractory phenomenon despite extensive anti-asthma treatment but is still sensitive to high-dose systemic corticosteroids
[23]. However, data in this field are conflicting and proof of the opposite has been reported, reviewed in [24]. Those severe asthmatics who suffer from frequent exacerbations differ from non-frequent exacerbators in terms of quality of life and sputum eosinophilia (Table S2). Thus, it may be hypothesized that this increase in exacerbation rate merely represents a continuum of severity related to eosinophilic inflammation and clinical control. The design of the current trial does not enable us to gain insight into the mechanisms underlying the observed differences and thus we do not discuss endotypes, instead we propose a new clinically defined phenotype. The most probable reasons for frequent exacerbations may include a lack of disease control with regards to eosinophilic inflammation (possibly due to a lack of compliance to medications, the use of inadequate doses of medications, glucocorticosteroid resistance, comorbidities, or other as yet unknown mechanisms. Nevertheless, we believe that it is important to identify this subpopulation of asthma patients in clinical practice. Such an approach enables us to evaluate the most probable reasons for frequent exacerbations, as well as identify this population for further mechanistic studies.

It could be argued that the reason for the high rate of exacerbations in our study is poor adherence to prescribed treatment. Several groups have shown that compliance with doctors' recommendations is one of the major problems in difficult-to-treat asthmatics. Genuine steroid unresponsiveness is rare [25] and in most cases $(30-60 \%)[26,27]$, poor control results from non-adherence, comorbidities, poor inhalation techniques or wrong diagnosis. However, in this study, good adherence to the recommended treatment was achieved by the involvement of highly devoted clinical centres, the treatment optimization period at inclusion, repeated instruction in inhalation technique, personalized treatment plans and the careful follow-up of all included patients. Nevertheless, adherence has not been evaluated using unbiased methods (such as the memory chips of meter dose inhalers), which is a clear limitation of our report. On the basis of the results of our study, we propose that high levels of exhaled NO or eosinophils in induced sputum along with low asthma control (evaluated using the Juniper ACQ) could be regarded as warning signals in our every day clinical practice. In such cases, adherence to the controller medication should be checked before any other therapeutical options are introduced.

Allocation of our patients to clusters based on previously published proposals $[12,13]$ revealed that most of the frequent exacerbators belong to a cluster with low baseline lung function which is partially reversible, or a cluster with a high baseline lung function that is not reversible, with early onset of the disease [12]. Taking 
biomarkers into consideration most of our frequent exacerbators belong to a cluster characterized by high sputum eosinophils with either high or low neutrophils [13]. When analysing baseline clinical characteristics, physiological variables and biomarkers, we found that those patients characterized by exhaled NO levels $>45$ p.p.b. and had a history of smoking represented a group of asthmatics at higher risk of frequent exacerbations. Again, this is in accordance with the NorthAmerican severe asthma network data [28]. What is particularly striking in our study is the tendency towards a steeper decline in lung function among the frequent exacerbators. The impact of exacerbations on decline in lung function has been reported in asthma [29] and COPD patients [14]. However, this finding requires confirmation in studies with follow-up periods longer than 1 year.

We did not find any significant differences in basic characteristics between seasonal (spring or autumn) and non-seasonal exacerbators; thus, the phenotype of seasonal exacerbator could not be distinguished in our study. Sputum eosinophils $\geq 2 \%$ and male sex were associated with a significantly higher risk of developing spring exacerbations, which is not surprising as those exacerbations are most probably associated with atopic status, allergen sensitization and allergen exposure [30], in contrast to autumn exacerbations, which are most likely associated with viral infections [31]. The BIOAIR study was a multi-centre, trans-European trial with patients included from Scandinavia to the Mediterranean region, with different allergies and different seasons of exposure. As patients experienced exacerbations in different months, it was difficult to clearly allocate seasonal or non-seasonal exacerbators, which is a limitation of our study. Moreover, viral infections may occur throughout the year (rhinovirus in the autumn, influenza in the late winter to early spring), making any seasonal predilection difficult to interpret.

The ability to identify patients with the greatest risk of future exacerbations is vital for developing effective preventive strategies, reducing health care costs and achieving good asthma control. In our article, we present the clinical characteristics of the frequent exacerbators' phenotype as well as the risk factors for frequent flare-ups of the disease. Methods such as exhaled NO measurement, are widely used, thus implementation of our findings into treatment guidelines would enable easier identification of patients who are at risk, increase monitoring and improve every day clinical care. Appropriate long-term management strategies coupled with improved compliance should reduce mortality and morbidity associated with asthma exacerbations [31, 32], however, further studies are needed to clarify the optimal treatment options for frequent exacerbators. The fact that this group of severe asthma patients, who are under specialist care in highly specialized centres still remain symptomatic and face frequent exacerbations, emphasizes the need for more research into pathogenetic mechanisms and novel therapeutic approaches.

\section{Acknowledgements}

The BIOAIR study was supported by The Fifth and Sixth Framework Programmes of the European Union, contract numbers: QLG1-CT-2000-01185 (BIOAIR) and F00D-CT-2004-506378 (GA2LEN), and several national funding bodies (Sweden: Heart-Lung Foundation and Asthma and Allergy Foundation; Greece: unrestricted competitive research grant 'The Herakleitos project 2002', from the Hellenic Ministry of Education; UK: Patrick Mallia was supported by unrestricted grant from GSK).

\section{Authors' contribution}

Primary data aggregation and statistical analyses were done by MK and SED, and then discussed and interpreted with the other co-authors at face-to-face meetings. MK wrote the first draft of the manuscript. Revisions were made by MK together with SED and in an interactive process including all co-authors. All authors participated in the study design, conduction of the trial, collection and interpretation of data, and critical review of the draft versions of the report.

\section{Conflict of interest}

Maciej Kupczyk was a scholarship fellow of the WennerGren Foundations and was supported by the Bernard Osher Initiative for Research on Severe Asthma at the Karolinska Institutet. The BIOAIR study received unconditional support from AstraZeneca Sweden, Vitalograph Inc, Aerocrine $\mathrm{AB}$, and Amedon $\mathrm{GmbH}$.

\section{References}

1 Martinez FD. Managing childhood asthma: challenge of preventing exacerbations. Pediatrics 2009; 123: S146-50.
2 Bel EH, Sousa A, Fleming L et al. Diagnosis and definition of severe refractory asthma: an international consensus statement from the Innovative Medicine Initiative (IMI). Thorax 2010; 66:910-7.
3 O'Byrne PM, Barnes PJ, RodriguezRoisin $\mathrm{R}$ et al. Low dose inhaled budesonide and formoterol in mild persistent asthma: the OPTIMA randomized trial. Am J respire Crit Care Med 2001; 164:1392-7. 
4 Reddel HK, Taylor DR, Bateman ED et al. An official American Thoracic Society/European Respiratory Society statement: asthma control and exacerbations. Am J Respir Crit Care Med 2009; 180:59-99.

5 Global Initiative for Asthma. Global strategy for asthma management and prevention 2008. Available at www.ginasthma.com (accessed on 22 June 2012).

6 Reddel H, Ware S, Marks G, Salome C, Jenkins C, Woolcock A. Differences between asthma exacerbations and poor asthma control. Lancet 1999; 353:364-9.

7 Wan ES, DeMeo DL, Hers CP et al. Clinical predictors of frequent exacerbations in subjects with severe chronic obstructive pulmonary disease (COPD). Respir Med 2011; 105:588-94.

8 ten Brinke A, Sterk PJ, Mascelee AAM et al. Risk factors of frequent exacerbations in difficult-to-treat asthma. Eur Respir J 2005; 26:812-8.

9 Juniper EF, O'Byrne PM, Guyatt GH, Ferrie PJ, King DR. Development and validation of a questionnaire to measure asthma control. Eur Respir J 1999; 14:902-7.

10 Jones PW, Quirk FH, Baveystock CM, Littlejohns P. A self-complete measure of health status for chronic airflow limitation. The St. George's Respiratory Questionnaire. Am Rev Respir Dis 1992; 145:1321-7.

11 The ENFUMOSA Study Group. The ENFUMOSA cross-sectional European multicentre study of the clinical phenotype of chronic severe asthma. Eur Respir J 2003; 22:470-7.

12 Moore WC, Meyers DA, Wenzel SE et al. Identification of asthma phenotypes using cluster analysis in the severe asthma research program. Am J Respir Crit Care Med 2010; 181:315-23.

13 Hastie AT, Moore WC, Meyers DA et al. Analyses of asthma severity phenotypes and inflammatory proteins in subjects stratified by sputum granulocytes. J Allergy Clin Immunol 2010; 125:1028-36.

14 Soler-Cataluna J, Rodriguez-Roisin R. Frequent chronic obstructive pulmonary disease exacerbators: how much real, how much fictious? COPD 2010; 7:276-84.

15 Butler C, Heaney LG. Risk factors of frequent exacerbations in difficult-totreat asthma. Eur Respir J 2006; 27:1324-5.

16 Moore WC, Bleecker ER, Curran-Everett $\mathrm{D}$ et al. Characterization of severe asthma phenotype by the National Heart, Lung and Blood Institute's Severe Asthma Research Program. J Allergy Clin Immunol 2007; 119:405-13.

17 Haselkorn T, Zeiger RS, Chipps BE et al. Recent asthma exacerbations predict future exacerbations in children with severe or difficult-to-treat asthma. $J$ Allergy Clin Immunol 2009; 124:921-7.

18 Miller MK, Lee JH, Blanc PD et al. TENOR risk score predicts healthcare in adults with severe or difficult-to-treat asthma. Eur Respir J 2006; 28:114555.

19 Bateman ED, Boushey HA, Bousquet J et al. Can guideline-defined asthma control be achieved? The Gaining Optional Asthma Control Study. Am J respire Crit Care Med 2004; 170:836-44.

20 Haldar P, Brightling CE, Hardagon B et al. Mepolizumab and exacerbations of refractory eosinophilic asthma. $N$ Engl J Med 2009; 360:973-84.

21 Samitas K, Rådinger $\mathrm{M}$, Bossios $\mathrm{A}$. Current update on eosinophilic lung diseases and anti-IL-5 treatment. Recent Pat Antiinfect Drug Discov 2011; 6:189-205.

22 Pavord ID, Korn S, Howarth $\mathrm{P}$ et al. Mepolizumab for severe eosinophilic asthma (DREAM): a multicenter, double-blind, placebo-controlled trial. Lancet 2012; 380:651-9.
23 ten Brinke A, Zwinderman AH, Sterk PJ, Rabe KF, Bel EH. "Refractory" eosinophilic airway inflammation in severe asthma. Am J Respir Crit Care Med 2004; 170:601-5.

24 Kupczyk M, Wenzel S. U.S. and European severe asthma cohorts: what can they teach us about severe asthma? J Intern Med 2012; 272: 121-32.

25 Chan MT, Leung DY, Szefler SJ, Spahn JD. Difficult-to control asthma: clinical characteristics of steroid-insensitive asthma. J Allergy Clin Immunol 1998; 101:594-601.

26 Heaney LG, Conway E, Kelly C et al. Predictors of therapy resistant asthma: outcome of a systemic evaluation protocol. Thorax 2003; 58:561-6.

27 Robinson DS, Campbel DA, Durham SR, Pfeffer J, Barnes PJ, Chung KF. Systematic assessment of difficult-totreat asthma. Eur Respir J 2003; 22:478-83.

28 Dweik RA, Sorkness RL, Wenzel S et al. Use of exhaled nitric oxide measurement to identify a reactive, at-risk phenotype among patients with asthma. Am J Respir Crit Care Med 2010; 181:1033-41.

29 0'Byrne PM, Pedersen S, Lamm CJ et al. Severe exacerbations and decline in lung function in asthma. Am J Respir Crit Care Med 2009; 179:19-24.

30 Jatakanon A, Lim S, Barnes PJ. Changes in sputum eosinophils predict loss of asthma control. Am J Respir Crit Care Med 2000; 16:64-72.

31 Sears MR. Epidemiology of asthma exacerbations. J Allergy Clin Immunol 2008; 122:662-8.

32 Schatz M, Zeiger RS, Vollmer WM, Mosen D, Cook EF. Determinants of future long-term asthma control. J Allergy Clin Immunol 2006; 118:1048-53.

\section{Appendix}

Amsterdam: Els Weersink; Athens: Nikos Papadopoulos, Erasmia Oikonomidou, Eleftherios Zervas; Ferrara: Marco Contoli; Ghent: Romain A. Pauwels (deceased), Guy F. Joos, Isabelle de Rudder, Vanessa Schelfhout; Hamburg/Grosshansdorf: Kai Richter, Daisy Gerding, Helgo Magnussen; Heraklion: Nikos M. Siafakas, Eleni
Tzortzaki, Katerina Samara, Maria Plataki, Eva Papadopouli; Krakow: Andrzej Szczeklik (deceased), Bozena Ziolkowska-Graca, Aleksander Kania, Agnieszka Gawlewicz-Mroczka, Mariusz Duplaga, Ewa Figiel; Leiden: Klaus F. Rabe, Pieter S. Hiemstra, Stefanie Gauw, Ilonka van Veen, Leuven: Johan C. Kips; London: Sebastian L. Johnston, Patrick Mallia, Deborah A. Campbell, Douglas S. Robinson; Luebeck: Frank 
Kanniess; Modena: Leo M. Fabbri, Micaela Romagnoli; Montpellier: Isabelle Vachier, Catherine Devautour, Lahouari Meziane; Palermo: A. Maurizio Vignola (deceased), Elisabetta Pace, Mirella Profita; Southampton: Stephen T. Holgate, Peter H. Howarth, Susan J. Wilson, Lorraine Hewitt, John Holoway; Stockholm: Roelinde J.M. Middelveld, Katarina Damm, Ingrid Delin, Marianne Eduards, Alexandra Ek, Tommy Ekström, Flora Gaber, Agneta Gülich, Anna James, Lovisa E. Johansson, Östen Karlsson, Maria Kumlin,
Ingrid Martling, Marianne Olsson, Maria Skedinger, Shushila Haque.

\section{Supporting Information}

Additional Supporting Information may be found in the online version of this article:

Data S1. Online repository materials. 